\title{
Production of Brugia malayi BmSXP recombinant protein expressed in Escherichia coli
}

\author{
Khoo, T. K. ${ }^{1}$, Santhanam, A. ${ }^{{ }^{\star}}$, Noordin, R. ${ }^{1}$ and Arifin, N. ${ }^{1}$ \\ Institute for Research in Molecular Medicine (INFORMM), Universiti Sains Malaysia (USM), 11800 Penang, Malaysia. \\ E-mail: amutha_santhanam@yahoo.com \\ Received 22 July 2009; received in revised form 25 September 2009; accepted 1 October 2009
}

\begin{abstract}
A rapid antibody detection test is very useful for detection of lymphatic filariasis, especially for certification and surveillance of post-mass drug administration. One such kit, panLF Rapid ${ }^{\mathrm{TM}}$ (commercialized by Malaysian BioDiagnostic Research Sdn. Bhd.) had been developed in our laboratory for the detection of all species of filarial infections. It is based on the detection of anti-filarial lgG4 antibodies that react with recombinant Brugia malayi antigens, $B m R 1$ and BmSXP. In this study, the growth of recombinant bacteria that produce BmSXP was optimized under shake flask fermentation for high yield of the recombinant antigen. The optimizations involved selection of suitable growth medium, IPTG concentration and induction time. The medium that yielded the highest biomass as well as total protein was Terrific Broth (TB) medium, which is an undefined medium. Initiation of induction of protein expression was found to be best at mid-log phase $\left(\mathrm{OD}_{600}=1.5\right)$, with IPTG concentration of $1.0 \mathrm{mM}$, and harvest time at $9 \mathrm{~h}$ post-induction. This study showed that under the optimized conditions, the shake flask culture produced $4 \mathrm{~g} / \mathrm{L}$ biomass (dry cell weight) of recombinant Escherichia coli BmSXP/pPROEXHTa/TOP10F', which yielded $2.42 \mathrm{mg} / \mathrm{L}$ of purified BmSXP recombinant antigen. The purified antigen was analyzed by SDS-PAGE and the antigenicity of protein was confirmed by Western blot.
\end{abstract}

Keywords: human lymphatic filariasis, BmSXP recombinant antigen, shake flask culture, IPTG

\section{INTRODUCTION}

Human lymphatic filariasis (LF) is mainly caused by three species of filarial nematodes namely Wuchereria bancrofti, Brugia malayi (B. malayi) and Brugia timori. Currently over 120 million people are already infected, with more than 40 million are incapacitated or disfigured with swollen limbs (lymphoedema) and genitals (hydrocele) (Addiss and Brady, 2007). The Global Programme to Eliminate Lymphatic Filariasis (GPELF) has been initiated by World Health Organization (WHO) in 1997 with two major goals, which is to interrupt transmission of the parasite and morbidity control by providing care for those who suffer the devastating clinical manifestations of the disease (Addiss and Brady, 2007). Improved methods for detection of filarial infections are needed to facilitate certification and surveillance activities of the GPELF and to evaluate new drugs. Commercially rapid antibody based detection test kits are now available to detect both kinds of lymphatic filariasis. The product, panLF Rapid ${ }^{T M}$ kit developed in our laboratory is based on the detection of anti-filarial IgG4 antibodies that react with recombinant $B$. malayi antigens, BmSXP and BmR1. Th recombinant antigen, BmSXP (derived from the ORF of SXP1 gene) (462 bp) had shown to be highly sensitive and specific $(>95 \%)$ as a diagnostic tool for the detection of brugian and bancroftian filariasis (Rahmah et al., 2007).

\footnotetext{
${ }^{\star}$ Corresponding author
}

Escherichia coli is commonly used to produce recombinant proteins because it can be grown to high densities on inexpensive media and its genetics has been well understood. These attributes led to the use of $E$. coli as the most popular host cell in bio fermentation. Although filarial parasite is a eukaryote, a prokaryotic expression system (E. coli) had been intentionally chosen for production of BmSXP recombinant protein based on two reasons. First, carbohydrate moieties on helminth antigens has been reported to contribute to serological cross-reactions (Yamano et al., 2009), thus an E. coli system is used because the proteins expressed do not have post translational modifications. Second, an E. coli expression system allows production of large amounts of recombinant proteins (Kathleen et al., 1996). However, synthesis of recombinant protein places substantial metabolic burden on the producing cells. In order to prevent this burden from compromising the growth, biomass production and protein production are separated by using transcription regulators. Common regulators used in $E$. coli include the lac, trp, araBAD and tac promoters (Makrides, 1996). The lac promoter used in this work is controlled by the use of isopropyl-B-Dthiogalactoside (IPTG) (Kweon et al., 2001). Recombinant protein production is normally induced in the late exponential growth phase. However, induction in the late exponential phase or early stationary phase reduces the culture viability and can lead to production of proteases

115

Present Address: Department of Genetic Engineering, School of Biotechnology, Madurai Kamaraj University, Madurai-625021, India. 
that can break down the desired recombinant protein. On the other hand, early induction can unnecessarily slow the doubling time of bacterial cells (Chisti, 1998; Corchero et al., 2001). Hence it is important to optimize the type of medium, IPTG concentration and induction time, to achieve high cell density culture towards the aim of producing a high yield of the recombinant protein.

Generally the development of fermentation strategies are focused on improving the cultivation techniques, manipulating the physiology of the bacteria and the level of recombinant protein expression.. As a result, batch and fed batch fermentation techniques have been developed (Shiloach and Fass, 2005). Optimization of the fermentation process to maximize the biomass production (and increase the yield of recombinant antigen) can be initiated with batch kinetics whereby specific nutrient types, temperature, pressure, aeration, and other environmental conditions are initially provided for a few generations of growth before all nutrients are used up and growth comes to a halt. The kinetic parameters of the batch culture system are useful for the determination of the behavior of bacterial strains; these parameters include substrate inhibition or catabolic repression. The information derived from studying the parameters sets the preliminaries to be further pursued when performing the fed-batch culture system (Liu et al., 2000).

The aim of this study is to optimize the growth conditions of the recombinant $E$. coli carrying BmSXP gene under shake flask culture to produce high yield of the recombinant protein.

\section{MATERIALS AND METHODS}

\section{Strain and plasmid}

The host strain used was E. coli TOP10F', and the expression vector was pPROEXHT ${ }^{\mathrm{TM}} \mathrm{HTa}$ (Life Technologies, USA). The recombinant bacteria, BmSXP/pPROEXHTa/TOP10F', was previously constructed in our laboratory by cloning the open reading frame (ORF) of the SXP1 gene (462 bp, GenBank accession no. M98813) from B. malayi cDNA library. After subcloning into the expression vector, the length of the nucleotides from start codon of the vector to the stop codon of the gene was $585 \mathrm{bp}$, which was translated to the BmSXP recombinant antigen. Inclusive of the $6 \times \mathrm{H}$ Histagged region, this sums up to a size of the recombinant antigen of approximately $22.1 \mathrm{kDa}$ (Rohana et al., 2007). Bacterial culture was maintained and sub-cultured on LB medium (with $100 \mu \mathrm{g} / \mathrm{mL}$ ampicillin). For long term storage the culture was stored in LB broth supplemented with 100 $\mu \mathrm{g} / \mathrm{mL}$ ampicillin and $20 \%$ glycerol stored at $-80^{\circ} \mathrm{C}$.

\section{Media and chemicals}

Reagents and chemicals were purchased from Merck (Darmstadt, Germany) and BioRad (Hercules, USA). Inoculum was grown in Luria-Bertani medium (LB) that contained the following: peptone $(10 \mathrm{~g} / \mathrm{L})$, yeast extract $(5$ $\mathrm{g} / \mathrm{L}), \mathrm{NaCl}(5 \mathrm{~g} / \mathrm{L})$ and the $\mathrm{pH}$ was adjusted to 7.0. Shake flask fermentations used modified Terrific broth (TB) that contained the following: tryptone $(12 \mathrm{~g} / \mathrm{L})$, yeast extract (24 g/L), peptone (12 g/L), $\mathrm{K}_{2} \mathrm{HPO}_{4}(12.5 \mathrm{~g} / \mathrm{L}), \mathrm{KH}_{2} \mathrm{PO}_{4}$ $(2.3 \mathrm{~g} / \mathrm{L})$, glucose $(5 \mathrm{~g} / \mathrm{L})$ and the $\mathrm{pH}$ was adjusted to 7.0 . The lac promoter used has been previously reported by Saluta and Bell (1998) to be a weak promoter with moderate levels of basal expression occurring under noninduced conditions. Basal expression generally is undesirable as it reduces the energy available for growth and, if the recombinant protein is toxic to the cells, this may lead to growth inhibition or death of the culture prior to achieving optimized cell density required for induction. Hence, to reduce the effects of basal expression, the TB broth was modified to replace glycerol with glucose (Guzman et al., 1995).

\section{Initial inoculum concentration}

A single colony of BmSXP/pPROEXHTa/TOP10F' was inoculated in $10 \mathrm{~mL}$ of $\mathrm{LB}$ broth followed by sub-culturing into $100 \mathrm{~mL}$ modified TB (supplemented with $100 \mu \mathrm{g} / \mathrm{mL}$ ampicillin) and incubated overnight $( \pm 16 \mathrm{~h})$ at $37^{\circ} \mathrm{C}$ at $210 \mathrm{rpm}$ in an incubator shaker. In order to optimize the initial inoculum, different concentrations of initial inoculum were varied at $1 \% \mathrm{v} / \mathrm{v}, 2 \% \mathrm{v} / \mathrm{v}, 5 \% \mathrm{v} / \mathrm{v}$ and $10 \% \mathrm{v} / \mathrm{v}$ of the recombinant bacteria in shake flask culture.

\section{Optimization of culture medium}

Media trials were performed to evaluate the BmSXP recombinant antigen production on several media that are commonly used for culturing $E$. coli. Triplicate cultures were performed in six different medium namely LuriaBertani broth (LB), Terrific broth (TB), Super broth (SB), Soybean-peptone yeast extract broth (SOB), Rich Medium (RM) and M9 minimal medium (Atlas, 1997). Culture working volume was set at $20 \%$ of total volume, where the optimized inoculum was added to $200 \mathrm{~mL}$ of each of the different medium in $1 \mathrm{~L}$ Erlenmeyer flask incubated at 210 rpm at $37{ }^{\circ} \mathrm{C}$. Samples were taken at regular time intervals. Cultures were induced with $1.0 \mathrm{mM}$ IPTG once the cell density reached $\left(\mathrm{OD}_{600}\right) 1.5$. The amounts of total cell protein, recombinant protein and biomass were measured at specific harvest time intervals.

\section{Optimization of inducer concentration}

To assess the effect of various concentrations of IPTG on the induction of the recombinant antigen synthesis, the optimized inoculum was introduced in $1 \mathrm{~L}$ shake flasks, each containing $200 \mathrm{~mL}$ of the optimized medium supplemented with $100 \mu \mathrm{g} / \mathrm{mL}$ ampicillin. Once the cell density reached $\left(\mathrm{OD}_{600}\right)$ 1.5, triplicate cultures were induced with $0.2,0.3,0.5,0.8,1.0,2.0$, and $3.0 \mathrm{mM}$ concentrations of IPTG. All cultures were incubated at 210 $\mathrm{rpm}$ and $37{ }^{\circ} \mathrm{C}$. The amounts of total cell protein, recombinant protein and biomass were measured. 


\section{Optimization of induction time}

To investigate the effect of induction time on the production of BmSXP, the optimized inoculum was added to $1 \mathrm{~L}$ shake flasks containing $200 \mathrm{~mL}$ of the optimized medium supplemented with $100 \mu \mathrm{g} / \mathrm{mL}$ ampicillin. Triplicate cultures were induced at initial ODs of $0.1,0.3$, $0.5,1.0,1.5$ and 2.0 using $1.0 \mathrm{mM}$ IPTG, at $210 \mathrm{rpm}$ and $37^{\circ} \mathrm{C}$. The amounts of total cell protein, recombinant protein and biomass were measured.

\section{Selection of post-induction temperature}

To investigate the impinging effect of post-induction temperature on the production of BmSXP recombinant antigen, the optimized inoculum was added to $200 \mathrm{~mL}$ working volume of the optimized medium supplemented with $100 \mu \mathrm{g} / \mathrm{mL}$ ampicillin in $1 \mathrm{~L}$ Erlenmeyer flasks. Two sets of triplicate cultures were prepared; one set was maintained at $37^{\circ} \mathrm{C}$ throughout the whole protein expression process. In the other set, the temperature post-induction was reduced from $37{ }^{\circ} \mathrm{C}$ to $30^{\circ} \mathrm{C}$. All cultures were placed on a shaker-incubator at $210 \mathrm{rpm}$. The amounts of total cell protein, recombinant protein and biomass were measured.

\section{Batch Culture}

Under optimized conditions, batch cultures were carried out in $1 \mathrm{~L}$ flasks containing $200 \mathrm{~mL}$ medium in triplicates. At the optimized harvest time, the amounts of biomass, total cell protein and recombinant protein were determined.

\section{Protein Recovery}

Cells were harvested by subjecting the culture to centrifugation at $10,000 \mathrm{~g}$ for $10 \mathrm{~min}$. The supernatant was discarded while the pellet was transferred to a preweighed $50 \mathrm{~mL}$ centrifuge tube. The wet weight of the cell pellet was measured and then kept at $-80^{\circ} \mathrm{C}$. Preparation of cleared $E$. coli lysate under native conditions was performed using a modified adaptation of the handbook provided by the Ni-NTA resin manufacturer (Qiagen, USA) (Qiagen, 2003).

Prior to use, the cell pellet was thawed for $15 \mathrm{~min}$ on ice. The cell pellet was then resuspended in lysis buffer (with $10 \mathrm{mM}$ imidazole) containing a cocktail of protease inhibitors (Roche, Germany) at a ratio $25: 1$, and lysozyme at $0.5 \mathrm{mg} / \mathrm{mL}$. The mixture was then incubated on ice for $30 \mathrm{~min}$. This preparation was sonicated on ice (Misonix Sonicator 3000, USA) using a microtip. Sonication time was set at $120 \mathrm{~s} / \mathrm{g}$ of wet cell weight, with $30 \mathrm{~s}$ bursts and $30 \mathrm{~s}$ cooling period between each burst. DNase I at 5 $\mu \mathrm{g} / \mathrm{mL}$ was added to the cell lysate and incubated on ice for 10-15 $\mathrm{min}$. The cell lysate was then centrifuged at $13,000 \mathrm{~g}$ for $30 \mathrm{~min}$ at $4^{\circ} \mathrm{C}$ in preparation for affinity chromatography.

\section{Purification of BmSXP recombinant antigen}

The purification of the 6xHis-tagged proteins from E. coli using Ni-NTA Super flow under native conditions was performed using FPLC (Fast Protein Liquid Chromatography) (Qiagen, 2003). A volume of $3 \mathrm{~mL}$ washed resin slurry was packed into an assembled empty spun column (Size sep ${ }^{\mathrm{TM}} 400$ spun columns sepharose CL-4B, Amersham Biosciences, Uppsala, Sweden). The resin was allowed to settle by allowing the wash buffer containing $20 \mathrm{mM}$ imidazole to flow through the outlet. The bed volume was measured before loading the cell lysate. Ten times bed volume of wash buffer containing 45 $\mathrm{mM}$ imidazole was allowed to flow through the outlet. The protein fractions were eluted using the elution buffer containing $250 \mathrm{mM}$ imidazole. Fractions were collected at $500 \mu \mathrm{L}$ each for up to 15 fractions. The protein concentration of each fraction was determined using BioRad Protein assay (BioRad, USA) at wavelength absorbance value of $595 \mathrm{~nm}$. Fractions with protein concentration $\geq 200 \mu \mathrm{g} / \mathrm{mL}$ were pooled and the concentration was redetermined using the BioRad reagent. The recombinant antigen was then stored at -80 ${ }^{\circ} \mathrm{C}$.

\section{Analytical Methods}

Biomass was monitored by measuring optical density at $600 \mathrm{~nm}$ using a spectrophotometer (Thermo Spectronic, USA). The dry cell weight (DCW) was estimated from a calibration curve that correlated experimentally measured dry weight to spectrophotometric measurement of optical density.

Total cell protein was estimated by BioRad Protein Assay (BioRad, USA), using protein standards comprising various concentrations of bovine serum albumin (Sigma, USA). Sodium dodecyl sulfate polyacrylamide gel electrophoresis (SDS-PAGE) of protein samples was carried out as described previously (Laemmli, 1970). The gels were stained with Coomassie Brilliant blue R-250 (BioRad, USA). Low molecular weight marker proteins were used as standards (BioRad Precision Plus Protein Standards Unstained, BioRad, USA).

Western blot was performed for detection of the Histagged recombinant antigen and confirmation of the protein antigenicity. The electrophoresed BmSXP recombinant antigen was transferred to a mixed ester nitrocellulose membrane (NitroBind; GE Water \& Process Technologies, USA) in alkaline transfer buffer $(25 \mathrm{mM}$ Tris-base, $190 \mathrm{mM}$ glycine, $10 \% \mathrm{v} / \mathrm{v}$ methanol) using the Trans-Blot SD (BioRad, USA). The membrane was then incubated in blocking solution $(100 \mathrm{mM}$ Tris- $\mathrm{HCl}, \mathrm{pH} 7.5$, $1.5 \mathrm{M} \mathrm{NaCl}, 0.2 \% \mathrm{v} / \mathrm{v}$ Tween-20, $5 \% \mathrm{w} / \mathrm{v}$ non-fat milk powder) for $1 \mathrm{~h}$ at $37^{\circ} \mathrm{C}$. The membrane was then washed in TBS buffer (100 mM Tris- $\mathrm{HCl}, \mathrm{pH} 7.5,1.5 \mathrm{M} \mathrm{NaCl}, 0.2$ $\% \mathrm{v} / \mathrm{v}$ Tween-20). For detection of the His-tagged protein, the membrane was incubated overnight at $4{ }^{\circ} \mathrm{C}$ in the HisTag antibody conjugated to horseradish peroxidase (HRP) (Novagen, USA) at 1:1500. For confirmation of antigenicity of the protein, the membrane was incubated 
overnight at $4{ }^{\circ} \mathrm{C}$ with serum sample from a patient infected with bancroftian filariasis and serum from a healthy subject. After a washing step, the membrane was incubated with monoclonal anti-human IgG4-HRP at 1: 1000 for 1 h. Chemiluminescent substrate (Roche Diagnostic, Germany) and X-ray films (Kodak, USA) were employed for development of the membrane blots.

\section{RESULTS AND DISCUSSION}

\section{Initial inoculum and culture medium}

The addition of different concentrations of initial inoculum $(1 \% \mathrm{v} / \mathrm{v}, 2 \% \mathrm{v} / \mathrm{v}, 5 \% \mathrm{v} / \mathrm{v}$ and $10 \% \mathrm{v} / \mathrm{v})$ of the recombinant bacteria BmSXP/pPROEXHTa/TOP10F' showed that there was no difference in the time taken $(6 \mathrm{~h})$ to reach the stationary phase. However, the maximum DCW obtained from $1 \%$ inoculum was $4.0 \mathrm{~g} / \mathrm{L}$, which was higher than those obtained with the other inoculums (Figure 1). Thus this shows that high concentration of initial inoculum inhibited the cell growth, and the optimal concentration of initial inoculum was found to be $1 \% \mathrm{v} / \mathrm{v}$.

The growth and protein production characteristics of the cell cultured on various media are given in Table 1. TB produced the highest final cell density followed by SB. The high cell densities obtained with SB and TB are likely due to these media being rich in yeast extract and phosphate salts compared to the other media. Yeast extract is a known source of trace components and can relieve cellular stress responses such as from the production of proteases during synthesis of the recombinant protein (Lim et al., 2000). Phosphate is known to be important for attaining high cell densities of $E$. coli as phosphates can easily become a limiting nutrient when provided in low doses (Korz et al., 1995). In addition, these phosphate salts could have provided a buffering capacity to prevent severe $\mathrm{pH}$ fluctuations that can adversely impinge on the normal metabolic activity. The amount of protein produced by TB was higher than all other media tested as it yielded the highest biomass and total protein production. This finding was consistent with the previous report of Manderson et al. (2006) which explained that the higher growth of bacterial cells in TB medium was due to the presence of readily accessible carbon and nitrogen sources, in addition to the availability of complex nutrients like yeast extract and bacto-tryptone.

LB produced the lowest biomass, however the amount of total protein was comparable to the other media The only chemically defined medium used was minimal medium (M9) which yielded poor growth, this may be due to the low glucose level in the medium. Chemically defined media are generally known to produce slower growth and lower protein titres than complex media (Zanette et al., 1998). Nonetheless application of chemically defined media in producing recombinant proteins is a common practice (Zhang and Greasham, 1999; Kweon et al., 2001) because these media attain more consistent titres, allow easier process control and monitoring and also it can simplify the down streaming process of the target protein. In this study the use of complex media is justified since the final product will be incorporated into non-invasive diagnostic test kits, thus do not require attainment of very high purity. After $14 \mathrm{~h}$ of growth, despite the increasing biomass, the total cell protein did not increase. The maximum protein production achievable in all the media averaged at approximately $9 \mathrm{~h}$ post-induction (12 $\mathrm{h}$ post-inoculation) which denoted the optimum culture harvest time.

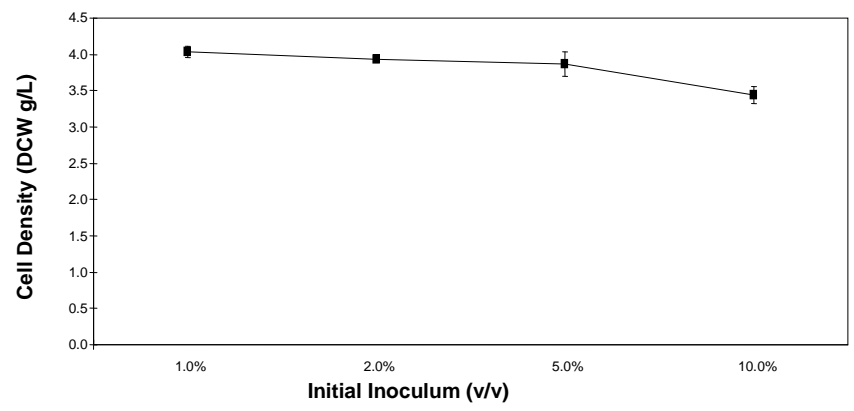

Figure 1: Growth Profile of BmSXP/pPROEXHTa/ TOP10F' cultured in Luria-Bertani broth (LB) medium at 9-hour culture

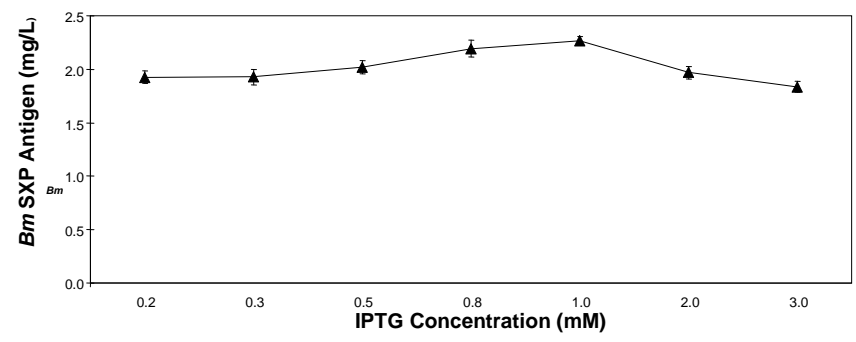

Figure 2: Production characteristics of $B m S X P /$ pPROEXHTa/TOP10F' expressing BmSXP recombinant antigen, at various inducer concentrations

\section{Optimization of inducer concentration}

Considering the high cost of IPTG, it is important to determine the minimum concentration that can optimally induce the lac promoter. The optimization of inducer concentrationtrials were conducted in TB since it was found to be the best medium. In previous studies on fermentation of other proteins, IPTG concentrations of between $0.2 \mathrm{mM}$ and $2.0 \mathrm{mM}$ have been used to induce the lac promoter (Li et al., 1999; Madurawe et al., 2000). However the concentration of IPTG required for complete induction is known to vary widely among clones. To produce $0.01 \mathrm{~g} / \mathrm{L}$ of decorin binding lipoprotein in E. coli, (Madurawe et al., 2000) used $0.1 \mathrm{mM}$ of IPTG for induction. On the contrary, Robbens et al. (1995) reported that recombinant $E$. coli required $2 \mathrm{mM}$ IPTG to produce $0.016 \mathrm{mg} / \mathrm{mL}$ of recombinant murine interleukin-2.

In the present study, the volumetric titre of recombinant antigen declined as the concentration of 
IPTG increased over the $1.0 \mathrm{mM}$ threshold (Figure 2). This was apparent because the presence of excessive IPTG reduced the final biomass as a consequence of the growth inhibition. Thus the results concurred with a previous report which found reduced growth rate in $E$. coli when the IPTG concentration exceeded $1.0 \mathrm{mM}$, but they had associated this to the toxic effect of the expressed

Table 1: Production characteristics of BmSXP/pPROEXHTa/TOP10F' expressing Total Cell Protein (TCP) cultured in various media

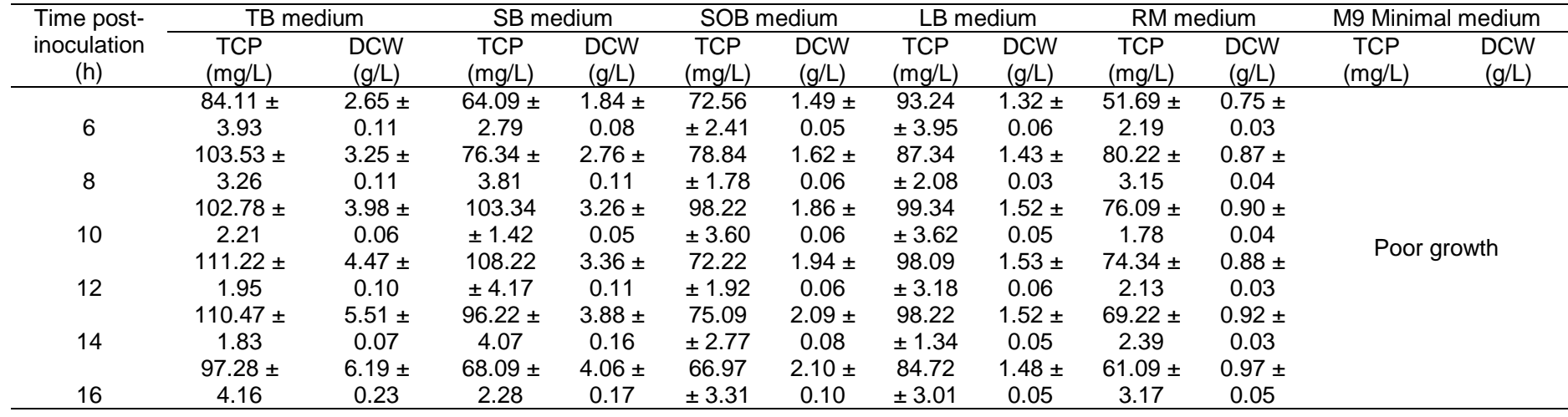

TCP- Total cell protein (mg/L), DCW- Dry Cell Weight $(\mathrm{g} / \mathrm{L})$

although expression of total protein using $0.5 \mathrm{mM}(2.1$ $\mathrm{mg} / \mathrm{L}), 0.8 \mathrm{mM}(2.2 \mathrm{mg} / \mathrm{L})$ and $1.0 \mathrm{mM}(2.3 \mathrm{mg} / \mathrm{L}) \mathrm{IPTG}$ were similar, the $1.0 \mathrm{mM}$ IPTG yielded the highest volumetric $B m S X P$ recombinant antigen production. Thus, $1.0 \mathrm{mM}$ IPTG was found to be the optimum inducer concentration and was used in all subsequent experiments.

\section{Optimization of induction time}

The expression of foreign genes in $E$. coli places substantial burden on the cell's metabolic system and limits the available energy for growth (Jeong and Lee, 1999). Cellular responses to induction depend on a number of interacting factors including the host/vector system and properties of the expressed protein. Therefore, the timing of induction of new recombinant proteins needs to be empirically determined for each new clone (CserjanPuschmann et al., 1999). The effect of induction time on the production of BmSXP recombinant antigen based on biomass production was determined, using cultures induced with the optimal concentration of $1.0 \mathrm{mM} \mathrm{IPTG}$. Figure 3 shows that the culture density at $\mathrm{OD}_{600} 1.5$ was the optimal induction time since it gave the highest volumetric titre of recombinant antigen. The volumetric titre increased as the uninduced period of growth was increased up to $\mathrm{OD}_{600} 1.5$, upon which it maximizes out. This result is consistent with Lim and Jung (1998) who found that recombinant protein production in $E$. coli fermentations was proportional to the growth rate at induction as the cell metabolic capacity is at its greatest during rapid growth. Induction at the onset of stationary phase appeared to reduce the volumetric yield of BmSXP recombinant antigen. Several studies reported that induction in the late exponential growth led to higher

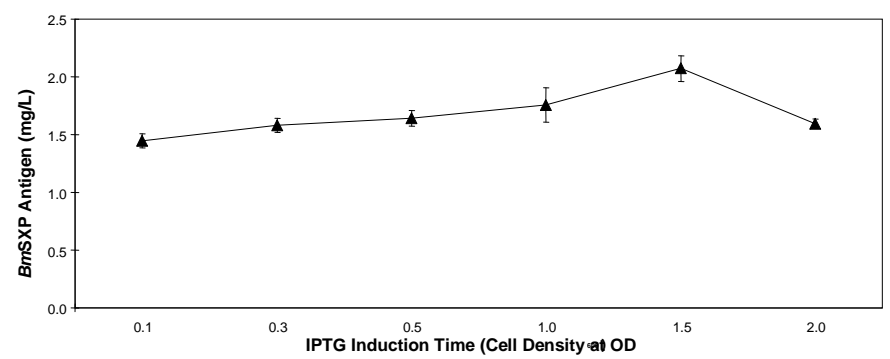

Figure 3: Production characteristics of $\mathrm{BmSXP} /$ pPROEXHTa/TOP10F' expressing BmSXP recombinant antigen, at various induction times

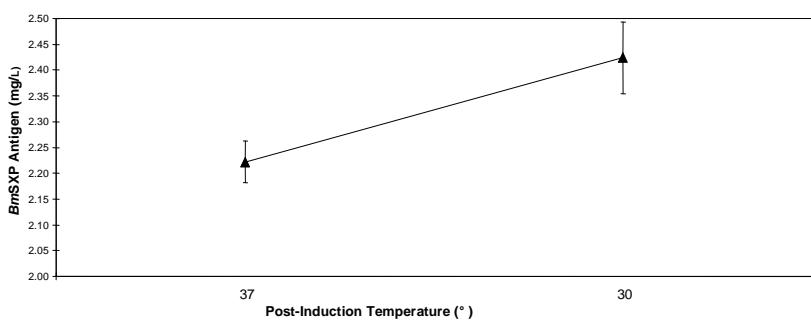

Figure 4: Production characteristics of $B m S X P /$ pPROEXHTa/TOP10F' expressing BmSXP recombinant antigen when culture temperature was changed from $37^{\circ} \mathrm{C}$ to $30^{\circ} \mathrm{C}$ during post induction

volumetric recombinant protein production by increasing the final cell density (Yee and Blanch, 1993; Zanette et al., 1998). Similar to the observation in this study, Yee and Blanch (1993) found that induction in late exponential 
growth and the onset of the stationary phase led to $50 \%$ greater recombinant trypsin being produced.

\section{Selection of post-induction temperature}

Depending on the recombinant protein being expressed, the effect of post-induction temperature is significant especially for temperature-sensitive proteins. Temperature inhibition affecting the protein expression process could cause the onslaught of protein denaturation. Several studies have also reported that low efficiency in active recombinant proteins recovery occurred when culture temperature was unchanged after induction due to formation of inclusion bodies, the latter is related to the high growth rate during the expression (Strandberg and Enfors, 1991; García-Junceda et al., 1995; Georgiou and Valax, 1996). Thus, lowering the culture temperature during expression of the protein may increase cellular responses to induction (Sariyar et al., 2004). In this study, cultures were induced with optimal concentration of 1.0 $\mathrm{mM}$ IPTG at $\mathrm{OD}_{600}$ 1.5. Reducing the culture temperature after the induction process from $37^{\circ} \mathrm{C}$ to $30^{\circ} \mathrm{C}$ caused an increase in volumetric titre of $B m S X P$ recombinant antigen (Figure 4). Comparison of the two temperatures using one-way ANOVA showed significant difference in the results $(p \leq 0.05)$. Post-induction temperature reduction has led to higher volumetric recombinant protein production by redirecting the cell's metabolic system to expressing the foreign gene, rather than performing the natural cellular responses of multiplication growth, while also suppressing the expression of other cellular proteins, and represses protease activity (Sariyar et al., 2004).

In addition, the SDS-PAGE analysis (Figure 5) showed fewer contaminating protein bands in lane 2 $\left(30{ }^{\circ} \mathrm{C}\right.$ at post-induction temperature) as compared to lane $1\left(37^{\circ} \mathrm{C}\right.$ post-induction temperature). This is in agreement with a previous study (Sariyar et al., 2004) which found that temperature down-shift allowed the cultured cells to switch the metabolic process to recombinant protein production, while suppressing the expression of other cellular proteins, and represses protease activity. The appearance of additional bands was most likely caused by the abundance of native host proteins which have histidine amino acid in its polypeptide chain, therefore resulting in the co-elution during FPLC purification (Sahoo et al., 2009). However, the Western blot evaluation performed in this study and previous data from one of our co-authors have reported a high diagnostic value of $B m S X P$, thus the co-eluted native host proteins do not affect the specificity of the recombinant antigen (Rahmah et al., 2007).

\section{Batch Culture}

Under the above optimized conditions, batch cultures were carried out in one litre flasks, each containing 200 $\mathrm{mL}$ medium, in order to determine the production of $B m S X P$ recombinant antigen. Once culture density reached $\mathrm{OD}_{600}$ 1.5, they were induced with $1.0 \mathrm{mM}$ IPTG and the temperature reduced to $30{ }^{\circ} \mathrm{C}$, followed by harvesting at $9 \mathrm{~h}$ post-induction. Under these optimized parameters, biomass production was $4 \mathrm{~g} / \mathrm{L}$ DCW of recombinant $E$. coli $B m S X P / p P R O E X H T a / T O P 10 F$, in which the maximum volumetric titre of $B m S X P$ recombinant antigen yielded $2.42 \mathrm{mg} / \mathrm{L}$ of purified $\mathrm{BmSXP}$ recombinant antigen.

\section{Western blot analysis of BmSXP recombinant antigen}

Western blot analysis using antibody to five-histidine conjugated to horse radish peroxidase (HRP) (Novagen, USA) showed good reactivity at $\sim 22.1 \mathrm{kDa}$, thus confirming the presence of the histidine-tagged recombinant antigen (Figure 6). The figure also clearly showed that the BmSXP recombinant antigen produced in this study was very antigenic when incubated with serum sample from a patient with bancroftian filariasis, and showed no reaction when incubated with normal serum. This study does not require the usage of serum samples from other helminthic infection, as previous published studies performed in multicenter evaluations have established high sensitivity and specificity of more than 95\% (Rahmah et al., 2007). In addition the presence of a single band on the Western blot confirmed the specificity of the BmSXP recombinant antigen.

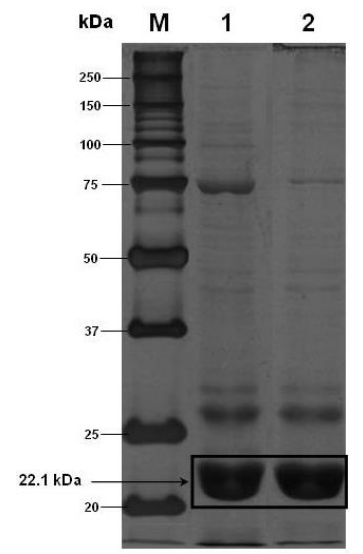

Figure 5: Comparison of SDS-PAGE results of purified $B m S X P$ recombinant antigen $(\sim 22.1 \mathrm{kDa})$ produced using different temperatures post induction : (M) Molecular weight marker; (1) $1.0 \mathrm{mM}$ IPTG induce at $\mathrm{OD}_{600} 1.5$, postInduction temperature maintained at $37^{\circ} \mathrm{C}$, harvested at $9 \mathrm{~h}$ post-induction; (2) $1.0 \mathrm{mM}$ IPTG induce at $\mathrm{OD}_{600} 1.5$, post-induction temperature dropped to $30^{\circ} \mathrm{C}$ harvested at 9 h post-induction 


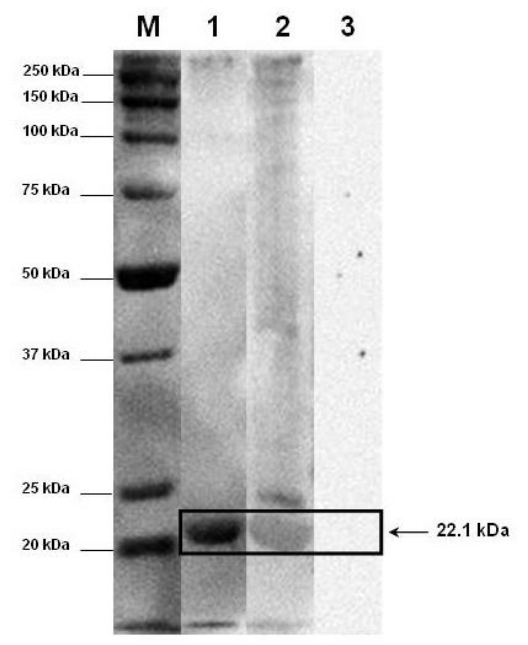

Figure 6: Western blot results of BmSXP recombinant antigen $(\sim 22.1 \mathrm{kDa})$ probed with various serum samples: (M) Molecular weight marker; (1) HisTag Antibody HRP Conjugate; (2) Serum from a $W$. bancrofti microfilaraemic patient; (3) Serum from a healthy individual

\section{CONCLUSION}

The production of BmSXP recombinant antigen was influenced by the type of medium, inducer concentration, induction time and post-induction temperature. The recombinant $E$. coli grown on Terrific Broth, a complex media rich in yeast extract and containing the phosphate buffer system, was found to support good growth and produce more recombinant protein as compared to the other media tested. IPTG concentration of $1.0 \mathrm{mM}$ was found to be sufficient to induce the lac promoter. Induction at $\mathrm{OD}_{600} 1.5$ produced the highest titre of $B m S X P$, and temperature reduction to $30^{\circ} \mathrm{C}$ after induction has allowed the cultured cells to switch the metabolic process to recombinant protein production, and produced high protein purity. Under the above optimized conditions, batch culture yielded $2.42 \mathrm{mg} / \mathrm{L}$ of the maximum volumetric titre of $B m S X P$ recombinant antigen from $4 \mathrm{~g} / \mathrm{L}$ DCW of recombinant $E$. coli BmSXP/pPROEXHTa/TOP10F', upon harvesting at $9 \mathrm{~h}$ post-induction. The protein produced under shake flask culture was also shown to be antigenic and thus suitable for diagnostic application. The shake flask culture data in this study thus can serve as a benchmark for comparisons in further fermentation developmental process using batch and fed-batch culture in a bioreactor.

\section{ACKNOWLEDGMENT}

This work was funded by a short term grant from Universiti Sains Malaysia, project number 304/CIPPM/638108.

\section{REFERENCES}

Addiss, D. G. and Brady, M. A. (2007). Morbidity management in the global programme to eliminate lymphatic filariasis: A review of the scientific literature. Filaria Journal 6, 1-19.

Atlas, R. M. (1997). Handbook of microbiological media. CRC Press, New York, USA.

Chisti, Y. (1998). Strategies In Downstream Processing. In: Subramanian, G. (ed.). Bioseparation and Bioprocessing: A Handbook. Vol 2. Wiley-VCH, New York. pp 3-30.

Corchero, J. L., Cubarsi, R., Vila, P., Aris, A. and Villaverde, A. (2001). Cell lysis in Escherichia coli cultures stimulates growth and biosynthesis of recombinant proteins in surviving cells. Microbiological Research 156, 13-18.

Cserjan-Puschmann, M., Kramer, W., Duerrschmid, E., Striedner, G. and Bayer, K. (1999). Metabolic approaches for the optimisation of recombinant fermentation processes. Applied Microbiology and Biotechnology 53, 43-50.

García-Junceda, E., Shen, G., Sugai, T. and Wong, C.H. (1995). A new strategy for the cloning, overexpression and one step purification of three DHAP dependent aldolases: rhamnulose-1phosphate aldolase, fuculose-1- phosphate aldolase and tagatose-1,6-diphosphate aldolase. Bioorganic and Medicinal Chemistry 3, 945-953.

Georgiou, G. and Valax, P. (1996). Expression of correctly folded proteins in Escherichia coli. Current Opinion in Biotechnology 7, 190-197.

Guzman, L-M., Belin, D., Carson, M. J. and Beckwith, J. (1995). Tight regulation, modulation, and high-level expression by vectors containing the arabinose PBAD promoter. Journal of Bacteriology 177, 4121-4130.

Jeong, K. J. and Lee, S. Y. (1999). High-level production of human leptin by fed-batch cultivation of recombinant Escherichia coli its purification. Applied and Environmental Microbiology 65, 3027-3032.

Kathleen, A. S., Timothy, J. H., Rajan,T. V. and Yates J. A.( 1996). Localization of paramyosin, myosin and heat shock protein 70 in larval and adult Brugia malayi. Journal of Parasitology 82, 367-370.

Korz, D. J., Rinas, U., Hellmuth, K., Sanders, E. A. and Deckwer, W-D. (1995). Simple fed-batch technique for high cell density cultivation of Escherichia coli. Journal of Biotechnology 39, 59-65.

Kweon, D. H., Han, N. S., Park, K. M. and Seo, J. H. (2001). Overproduction of Phytolacca insularis protein in batch and fed-batch culture of recombinant Escherichia coli. Process Biochemistry 36, 537-542.

Laemmli, U. K. (1970). Cleavage of structural proteins during the assembly of the head of bacteriophage T4. Nature 227, 680-685.

Li, N., Qu, L-J., Liu, Y., Li, Q., Gu, H. and Chen, Z. (1999). The refolding, purification, and activity analysis of a rice Bowman-Birk inhibitor expressed in Escherichia coli. Protein Expression and Purification 15, 99-104. 
Lim, H-K., Jung, K-H., Park, D-H. and Chung, S-I. (2000). Production characteristics of interferon-a using an I-arabinose promoter system in a high-celldensity culture. Applied Microbiology and Biotechnology 53, 201-208.

Lim, H-K. and Jung, K-H. (1998). Improvement of heterologous protein productivity by controlling postinduction specific growth rate in recombinant Escherichia coli under control of the PL promoter. Biotechnology Progress 14, 548-553.

Liu, Y. C., Liao, L. C. and Wu, W. T. (2000). Cultivation of recombinant Escherichia coli to achieve high cell density with a high level of penicillin G acylase activity. Proceedings of the National Science Council, Republic of China 24, 156-160.

Madurawe, R. D., Chase, T. E., Tsao, E. I. and Bentley, W. E. (2000). A recombinant lipoprotein antigen against Lyme disease expressed in E. coli: Fermentor operating strategies for improved yield. Biotechnology Progress 16, 571-576.

Makrides, S. C. (1996). Strategies for achieving high-level expression of genes in Escherichia coli. Microbiological Review 60, 512-538.

Manderson, D., Dempster, R. and Chisti, Y. (2006). A recombinant vaccine against hydatidosis: Production of the antigen in Escherichia coli. Journal of Industrial Microbiology and Biotechnology 33, 173-182.

QIAGEN (2003). The QIAexpressionist - A handbook for high-level expression and purification of $6 x \mathrm{His}$-tagged proteins. $5^{\text {th }}$ edn. pp. 79-85.

Rahmah, N., Itoh, M., Kimura, E., Rohana, A.R. Ravindran, B., Rohela, M., Supali, T. and Weerasooriya, M.V. (2007). Multi centre evaluations of two new rapid IgG4 tests (WBRapid and panLFRapid) for detection of lymphatic filariasis. Filaria Journal 6, 1-4.

Rahmah, N., Rohana, A. R. and Cheah, H. Y. (2007). Pan LF-ELISA using BmR1 and BmSXP recombinant antigens for detection of lymphatic filariasis. Filaria Journal 6, 1-7.

Robbens, J., Raeymaekers, A., Steidler, L., Fiers, W. and Remaut, E. (1995). Production of soluble and active recombinant murine interleukin-2 in Escherichia coli: High level expression, kil-induced release, and purification. Protein Expression and Purification 6, 481-486.

Rohana, A. R., Cheah H-Y. and Rahmah, N. (2007). Pan LF-ELISA using BmR1 and BmSXP recombinant antigens for detection of lymphatic filariasis. Filaria Journal 6, 1-7.

Sahoo, D., Andersson, J. and Mattiasson, B. (2009). Immobilized metal affinity chromatography in openloop simulated moving bed technology: Purification of a heat stable histidine tagged $\beta$-glucosidase. Journal Chromatography $B$ 877, 1651-1656.

Saluta, M. and Bell, P.A. (1998). Troubleshooting GST fusion protein expression in $E$. coli. Life Science News 1, 1-3.
Shiloach, J. and Fass, R. (2005). Growing E. coli to high cell density - A historical perspective on method development. Biotechnology Advances 23, 345-357.

Sariyar, B., Özkan, P., Kirdar, B. and Hortaçsu, A. (2004). Expression and translocation of glucose isomerase as a fusion protein in E. coli. Enzyme and Microbial Technology 35, 105-112.

Strandberg, L. and Enfors, S. O. (1991). Factors influencing inclusion body formation in the production of a fused protein in Escherichia coli. Applied and Environmental Microbiology 57, 1669-1674.

Yamano, K., Goto, A., Nakamura-Uchiyama, F., Nawa, Y., Hada, N. and Takeda T. (2009). Galbeta1-6Gal, antigenic epitope which accounts for serological cross-reaction in diagnosis of Echinococcus multilocularis infection. Parasite Immunology 31(8), 481-487.

Yee, L. and Blanch, H. W. (1993). Recombinant trypsin production in high cell density fed-batch cultures of Escherichia coli. Biotechnology and Bioengineering 41, 781-790.

Zanette, D., Dundon, W., Soffientini, A., Sottani, C., Marinelli, F., Akeson, A. and Sarubbi, E. (1998). Human IL-1 receptor antagonist from Escherichia coli: Large-scale microbial growth and protein purification. Journal of Biotechnology 64, 187-196.

Zhang, J. and Greasham, R. (1999). Chemically defined media for commercial fermentations. Applied Microbiology and Biotechnology 51, 407-421. 